\section{Klassiker der Moderne}

Heute gehört Döblin unbestritten zu den bedeutendsten Vertretern der Klassischen Moderne und hat seinen festen Platz in der Literaturgeschichte des 20. Jahrhunderts. Bis zu dieser Kanonisierung war es jedoch ein weiter Weg, wie der Blick auf die Rezeptionsgeschichte seines weit verzweigten Euvres zeigt. Döblins Texte haben seit ihrem Erscheinen das zeitgenössische Publikum und die Kritik polarisiert, bisweilen sogar provoziert, und der Autor selbst fühlte sich nicht selten unterschätzt oder missverstanden, sodass er sich zu Klarstellungen genötigt sah oder auch zu mehr oder minder polemischen Gegenattacken ausholte (vgl. z. B. Der Epiker, sein Stoff und die Kritik, April 1921, SLW 25-36). Indem er in poetologischen Essays die Entstehung seiner Werke und deren Intentionen ausführlich erläuterte, versuchte er immer wieder mit den ihm zur Verfügung stehenden publizistischen Mitteln, Lektürehilfen zu geben und die Rezeption in die gewünschte Richtung zu lenken. Diese wurde in erheblichem Maße beeinflusst von historischen Umbrüchen und Weltkriegen, die zu verzögerter Auslieferung von Büchern führten oder eine extrem geringe Resonanz zur Folge hatten; Letzteres gilt vor allem für die literarische Produktion im Exil zwischen 1933 und 1945. So ist die Wirkungsgeschichte Döblins auch ein Spiegelbild des jeweiligen zeit-, gesellschafts- und kulturgeschichtlichen Umfeldes, das in einigen Lebensphasen nicht eben günstig für seine oft sperrigen Werke war. Als kompromissloser Autor, der mit vielen seiner Texte sowohl thematisch als auch ästhetisch seiner Zeit voraus war, machte und macht er es seiner Leserschaft nicht immer leicht, ihm auf seinen verschlungenen Wegen des Denkens und Schreibens zu folgen.

\section{Rezeption zu Lebzeiten}

In seinen Anfangsjahren erwies sich vor allem der freundschaftliche Kontakt und künstlerische Austausch mit Herwarth Walden als zukunftsträchtig. Wie der Freund, der zu Beginn des 20. Jahrhunderts unermüdlich neue Publikations- und Kommunikationsforen zu etablieren suchte und sich als Kunstförderer profilierte, bewegte sich auch Döblin in inspirierenden Avantgarde-Zirkeln. Insbesondere durch die fruchtbare Kooperation in der frühexpressionistischen Phase der Zeitschrift Der Sturm, in der Döblin in den Jahren 1910 bis 1913 eine Vielzahl von Erzählungen und Feuilletons sowie die musikphilosophischen Gespräche mit Kalypso und den Roman Der schwarze Vorhang abdrucken ließ, konnte er sich als experimentierfreudiger Autor, eigenwilliger und respektloser Kritiker positionieren und Netzwerke in Kunst- und Kulturkreisen aufbauen.

Seine größtenteils im Sturm erstveröffentlichten Erzählungen bündelte Döblin zu einem Zyklus, der Ende 1912 unter dem Titel Die Ermordung einer Butterblume und andere Erzählungen im Münchner Verlag Georg Müller erschien und ihm positive Rezensionen eintrug. Lobend hervorgehoben wurden vor allem Döblins Fantasie und Originalität, seine plastische Sprache und das dynamisierte Erzähltempo. Dass Döblin damit tatsächlich, wie Albert Ehrenstein hervorhob, »zukunftsfähige epische Prosa (Schuster/ Bode 1973, 10) verfasst hatte, zeigte sich in aller Deutlichkeit nach Erscheinen des »chinesischen Romans" Die drei Sprünge des Wang-lun, der trotz verzögerter Auslieferung mitten im Ersten Weltkrieg ein breites Echo in allen bedeutenden Periodika fand. Der vom Autor aus werkbiografischer Sicht als eine Art »Dammbruch « (SLW 36) eingestufte Roman hat diesen Stellenwert auch aus rezeptionsgeschichtlicher Perspektive, wie sich an den größtenteils lobenden, teilweise sogar enthusiastischen Besprechungen ablesen lässt. Die Veröffentlichung im S. Fischer Verlag, der ab $1915 \mathrm{zu}$ Döblins verlegerischer Heimat geworden war, trug gewiss zur erhöhten Aufmerksamkeit für den Autor und sein Werk bei, ferner die Verleihung des renommierten Fontane-Preises im August 1916.

Die Qualitätsmaßstäbe, die Döblin mit seinem Wang-lun gesetzt hatte, blieben in der Bewertung sei- 